\title{
Comparison and cost benefit analysis of different data sets used for determining mollusc evolution: a case study of the cryptobranch nudibranch Halgerda (Mollusca: Gastropoda)
}

\author{
Shireen J. Fahey \\ Department of Invertebrate Zoology and Geology, California Academy of Sciences, 875 Howard Street, \\ San Francisco, California, 94103 USA. email: sfahey@calacademy.org
}

\begin{abstract}
Several approaches to examining the evolution of organisms have been tested over the past several decades. Specifically, morphological and molecular (DNA sequences) data sets are the most widely used methods to test a phylogenetic hypothesis. A cost benefit analysis of previously published studies of nudibranch mollusc phylogeny is presented. The previous studies utilized different types of data sets to derive hypotheses of relationships. The present cost benefit analysis examines the usefulness of the different data sets to verify an existing species level phylogeny. The existing hypothesis had been derived from morphological data only. Results of the present analysis indicate that two of the four data sets used, DNA sequence data and morphological characters, are the most effective when measured in terms of robustness of the resultant phylogeny and considering cost and time spent on the analysis. The other two data sets: sperm morphology and natural product chemistry were found to be valuable at higher taxonomic levels. Conclusions from the cost benefit analysis indicate that combinations of data can provide valuable insight into evolutionary relationships, allowing the researcher to further examine a hypothesis from various perspectives. Those perspectives include the molecular evolution of the organism, morphological character evolution, chemical evolution and reproductive evolution at a cellular level. Using a multidisciplinary approach to systematics reveals the complexities of evolution.
\end{abstract}

\section{INTRODUCTION}

Evolutionary biologists have proposed that phylogenetic hypotheses based on as many independent lines of evidence as possible provide the strongest support for the hypothesis (Farris 1983; Avise 1994; Ponder and Lindberg 1995; Moritz and Hillis 1996). Lines of evidence that have been considered in previous phylogenetic studies include morphological (using gross anatomy as well as cellular level data, such as sperm ultrastructure and histological examination of organs), molecular (using a variety of mitochondrial and nuclear genes) and ecological. Since evolution occurs in a variety of ways, as evidenced from the many previous studies (See for example the studies by the above referenced authors and Bremer and Struwe 1992; Ballard and Whitlock 2004), it would seem that a multi-dimensional approach would yield verified phylogenies. Certainly, more refined tools are now available to resolve evolutionary hypotheses, such as natural product chemistry, combinations of gene sequences and phyloecology (Cimino and Ghiselin 2001; Wägele et al. 2003; Valdés 2004).

One particularly beneficial use of multiple data sets is that poorly resolved nodes in a phylogenetic tree can be identified and examined so that future research can be designed to assist in resolving those nodes (Hillis 1987; Ponder and Lindberg 1995). If phylogeny is intended as the basis of classification and hypothesis testing (de Queiroz and Gauthier 1990), the highest level of resolution is a desirable and necessary goal. However, there can be a tradeoff between pursuing an ever more robust hypothesis and efficiency of time as well as finite research dollars, as found during the present analysis.

Robustness, as defined for the present analysis, refers to strength of support for a phylogenetic tree as measured by Bremer support (Bremer 1994) for example. Penny et al. (1991) noted that tree-building methods must not only be robust and efficient, but fast and falsifiable. So, for the present analysis, efficiency means the ability to accomplish one's goal (of having a reliable test or measure in this case) in a reasonable amount of time, with minimum expense or waste. The definition of cost for the present analysis is in terms of actual dollars required to complete the analyses.

The present cost benefit analysis examines phylogenetic robustness achieved by each of the data sets (both individually and combined) 
discussed herein, the efficiency of using each of the different data sets individually and of combining these data sets to examine a phylogenetic hypothesis of an organism.

Although comparative morphology has historically formed the basis of taxonomy, it is now considered by some investigators to be a rather crude means of discriminating organisms. See for example the discussion in Hillis (1987); Cracraft and Helm-Bychowski (1991) and de Queiroz et al. (1995). However the question is, will more refined methods, such as DNA sequencing render morphological studies as obsolete? Although molecular analysis has given us a new approach to study evolutionary relationships, even the cleverest observer cannot determine a DNA sequence without sophisticated tools and techniques. Thus there are limitations to some researchers due to cost and skill level. In the present analysis, four data sets (morphology, sperm ultrastructure, natural product chemistry and one mitochondrial gene sequence) are examined as used in taxonomy and systematics. Each data set is rated for robustness, cost and efficiency as defined above. The nudibranch mollusc Halgerda Bergh, 1880 (Discodorididae Bergh, 1891) serves as the model organism in the cost benefit analysis. Halgerda was chosen because a reasonably well-resolved phylogenetic hypothesis, based on morphological data is available for this group (Fahey and Gosliner 2001). The existing morphological hypothesis serves as the starting point for the present analysis, and the three additional data sets (sperm ultrastructure, natural product chemistry and one mitochondrial gene) are applied for the cost benefit analysis discussed above. For further details on the various components used for the analysis (Halgerda phylogenetics using morphology, natural product chemistry, sperm morphology and/or mitochondrial DNA sequences) see Fahey and Garson, 2002; Fahey 2003a and b; Fahey and Healy, 2003. A review of the published literature describing applications of the data sets for the present cost benefit analysis is presented.

\section{Gastropoda, Opisthobranchia systematics combining traditional morphological and molecular data sets}

Previous authors have recommended that a combination of molecular and morphological methods be used to provide robust phylogenetic hypotheses (e.g. Hillis 1987; Ponder and Lindberg 1995; Wägele et al 2003). More specifically, Ponder and Lindberg encouraged a collaborative effort to test the current phylogenies of the Gastropoda, one that uses an integrated approach. Particularly, they suggested that this effort would include new and existing cytological, morphological and molecular data in analyses of phylogenetic relationships.
The literature contains considerable disagreement over combined versus separate analysis of molecular and morphological data (see Hillis 1987; Swofford 1991; de Queiroz et al. 1995; Nixon and Carpenter 1996). However, Ponder and Lindberg (1995) state that whether or not the data are analyzed together or separately to test congruence, is a matter of personal choice of the researcher. Ponder and Lindberg believe that examining the degree of congruence in two independently acquired data sets is the way to test the robustness of a hypothesis; whether the data sets are morphological and molecular, or by comparing different sequence data, or by conducting a total evidence analysis (e.g. Swofford 1991; Ponder and Lindberg 1995; Moritz and Hillis 1996; Wägele et al. 2003).

Morphological characters have traditionally been used to develop phylogenies for opisthobranchs (including at the species level). Indeed, several phylogenies of dorid nudibranchs have been proposed that utilize morphological characters exclusively (e.g. Gosliner and Johnson 1994; Gosliner 1996; Gosliner and Johnson 1999; Valdés and Gosliner 1999; Fahey and Gosliner 2001; Garovoy et al. 2001; Valdés and Gosliner 2001; Dorgan et al. 2002; Valdés 2002; Gosliner 2004). The phylogenetic trees derived from these analyses were not compared to trees developed from other data sets such as natural product chemistry or sperm ultrastructure.

\section{DNA sequence data}

More recent publications have hypothesized opisthobranch phylogenies based exclusively on molecular (DNA sequence) characters (e.g. Thollesson 1998, 1999a and b; Medina and Walsh 2000; Wollscheid-Lengeling et al. 2001; Grande et al. 2004). These publications did not include comparisons of the molecular-derived trees to phylogenies developed from morphological data. However, Wollscheid-Lengeling et al. (2001) and Grande et al. (2004) did discuss their results in view of previous cladistic analyses based on morphology.

\section{Sperm ultrastructure data}

Sperm ultrastructure has proven very instructive for resolving gastropod and other molluscan systematics and phylogeny below species level (Giusti 1971; Giusti and Selmi 1982; Healy 1984; Healy and Willan 1984; Kohnert and Storch 1984; Koike 1985; Healy 1988a and b; Hodgson and Bernard 1988). However, previous studies have not demonstrated that sperm ultrastructure has a comparable phylogenetic signal at the species level of nudibranchs (Fahey and Healy 2003; Fahey 2003b).

There have been a number of transmission electron microscopical (TEM) studies dealing with 
sperm or spermiogenesis of nudibranchs (Thompson 1966; Schmekel 1971; Holman 1972; Thompson 1973; Eckelbarger and Eyster 1981; Eckelbarger 1982; Medina et al. 1985 and 1986; Healy and Willan 1991; Wilson and Healy 2002). The majority of these authors either limited their study to a single group of Nudibranch (Thompson 1966 and 1973; Holman 1972; Eckelbarger and Eyster 1981; Medina et al. 1985 and 1986) and/ or confined their study to a single structure within the sperm (Schmekel 1971). No previous phylogeny has examined sperm ultrastructure across a genus of nudibranch. However, both Healy and Willan (1991) and Wägele and Willan (2000) acknowledged sperm morphology as a very valuable character. Healy and Willan (1991) examined sperm ultrastructure of 27 nudibranchs representing the two suborders (Anthobranchia and Cladobranchia) and four superfamilies (Doridoidea, Dendronotoidea, Arminoidea, Aeolidoidea) of the Nudibranchia. Although Healy and Willan's examination found no related sperm synapomorphies uniting the Nudibranchia, their data did shed new light on possible relationships within the Doridoidea. Wilson and Healy (2002) examined a family of Nudibranchia (Chromodorididae) and found a sperm synapomorphy uniting the group. These authors suggested that acrosomal morphology might be taxonomically informative among nudibranch genera. No phylogenetic analyses have been published at the nudibranch species level using sperm morphology.

\section{Natural product chemistry as a taxonomic indicator}

Natural products have infrequently been used as taxonomic tools to characterize marine mollusc groups (Brunckhorst 1993; Valdés; Gosliner 1999). Indeed, most researchers to date, with some significant exceptions (Cimino et al. 1999; Cimino and Ghiselin 1999; Cimino and Ghiselin 2001), utilize the biochemistry of opisthobranchs not as an evolutionary tool, but as a method by which to determine the origin of various compounds within the mollusc, e.g. dietary derived vs. de novo synthesis. Since the 1970's, the literature describing natural product chemistry of marine molluscs has expanded considerably (for thorough reviews, see Faulkner 1996, 1997, 1998, 1999, 2000a and b, 2001). Since Idler et al. (1978) discussed the possibilities of using sterols from marine molluscs for taxonomy, only a few authors have followed with chemical studies of opisthobranchs that included taxonomic considerations (Faulkner and Ghiselin 1983; Karuso 1987; Avila 1992). A major reason for this lack of taxonomically related biochemical studies of opisthobranchs according to Cimino and Sodano (1994) is the lack of a definitive or error free classification. Past taxonomic classifications were often based only on external appearance or inadequate descriptions of internal features (see for example Bergh 1891). This lack of taxonomic information leads to confusion and disagreement on the identity of particular groups (e.g. Fahey and Gosliner 2003). Karuso (1987) stated that because the taxonomy of opisthobranchs is still fluid, it is currently difficult to make any definitive statements about the use of chemicals as taxonomic markers. However, Cimino and Ghiselin (2001) comment on recent studies using marine natural products to reveal evolutionary patterns in opisthobranchs (Cimino and Ghiselin 1998; Cimino and Ghiselin 1999).

Not only have natural products been used infrequently as taxonomic tools in opisthobranchs in general, even fewer recent systematic studies have included chemical characters in modern phylogenetic analyses of dorid nudibranchs specifically. The exceptions to this are the studies by Brunckhorst (1993) and Valdés and Gosliner (1999). In these two publications, the absence or presence of chemicals, used presumably for defense, is used as a taxonomic character or characters. Valdés and Gosliner (1999) also characterize the chemicals derived from a nudibranch as being either diet derived or from de novo synthesis.

Cimino and Ghiselin (1999) conclude that there is a weak correlation between the lineage of spongeeating dorid nudibranchs and the defensive chemicals isolated from them. However, these authors present evidence that combining chemical data with morphological data can offer insight into the evolution of the Nudibranchia and their closest relatives (Cimino and Ghiselin 1998 and 1999). But, no phylogenetic analysis was provided in these publications. In summary, it is not clear at the present time that natural product chemistry will be able to elucidate evolutionary relationships at the species level (e.g. Fahey, 2003b).

\section{METHODS}

The model taxon used for this study is the tropical, cryptobranch nudibranch genus Halgerda Bergh, 1880. The systematics and phylogeny of this discodoridid have previously been described using traditional morphology-based data (Fahey and Gosliner 2001). No systematic studies of the nudibranchs published to date have completed a species-level comparison between morphologyderived and molecular-derived (mtDNA sequences) phylogenies to resolve taxonomic or phylogenetic questions. Further, no taxonomic or systematic study of the Nudibranchia has combined three independently acquired data sets to test the robustness of a phylogenetic hypothesis. 
The present cost benefit analysis first reviews recent literature for examples of each of the four data sets considered for the present analysis (morphology, sperm ultrastructure, DNA sequences and natural product chemistry).

Secondly, four recently published nudibranchrelated data sets, DNA sequences (cytochrome oxidase I (COI)) (Fahey 2003b), histological data (sperm ultrastructure) (Fahey and Healy 2003) and biochemical data (natural product chemistry) (Fahey and Garson 2002; Fahey 2003a) to determine their particular usefulness (individually and in combinations) to provide a more resolved or robust phylogenetic hypothesis at the species level. Each data set was examined separately and then compared to the existing morphologically derived phylogenetic hypothesis of the model organism taken from Fahey and Gosliner 2001.

The present cost benefit analysis answers the following questions. Does combining these different data sets provide further insight into the evolutionary relationships among the species of a model organism? Can a researcher achieve a more robust hypothesis by combining data sets? What can be said about the efficiency and cost of deriving these particular data sets within the time constraints of a typical research project, such as specified by most grants or postgraduate programs? The cost benefit analysis can be applied to other nudibranch mollusk research projects to assist future researchers in determining the usefulness of each of the data sets.

Each of the four criteria of the cost benefit analysis (cost, time investment, efficiency and robustness of the phylogeny) is first defined and examples provided. The method for determining the assigned ratings shown in Table 1 is outlined.

\section{Definition of terms, considerations, examples and rating scales}

1. Cost $=$ Expense in terms of dollars for resources such as consumables, required fieldwork, transportation of collected specimens and some equipment and software.

The cost rating in Table 1 assumes that some specimens are available from institute collections. Having some or all material available will increase (i.e. improve) the number rating due to the cost of the fieldwork component. If the organism has not been previously studied and/or is rare, then the fieldwork component will be a major expense. Therefore, unless a researcher has access to material that has been stored in EtOH without formalin, (for sequence data) or either frozen, stored in acetone or methanol (for chemical extraction) or stored in glutaraldehyde (for ultrastructural examination), then fieldwork will be a major cost consideration.

Collection permit requirements can increase costs. Permits are required in most localities for collection and/or exporting organisms. Thus there is a possible cost associated with the application and/or permit fees.

Proper preservation and storage of organisms for data acquisition are other considerations for cost. For example, when preserving specimens for ultrastructural (TEM) examination, glutaraldehyde is required. However, only the organism's gonad needs to be collected and stored in this way, so small amounts of the chemical are all that is required. But refrigeration $\left(\leq 4^{\circ} \mathrm{C}\right)$ is recommended for at least the first 24 hours after immersion in the gluteraldehyde.

Collection is further encumbered by having to deal with either toxic chemicals out of a laboratory environment, or the unavailability of cold-storage equipment. Specimens preserved for chemical analysis require either freezing $\left(-20-70^{\circ} \mathrm{C}\right)$ or preservation in acetone or $100 \%$ methanol. Refrigerators with a capacity to go below $4^{\circ} \mathrm{C}$ or freezers below $-20^{\circ} \mathrm{C}$ are not always available in the field.

It is assumed that the researcher would have access to a modern lab with the necessary equipment to perform the analyses for each of the three data sets, whether it is a molecular laboratory, microscopy facility, or organic chemical laboratory. The laboratory should be evaluated in terms of availability of high-speed computers, with adequate storage to run phylogenetic analysis programs. Some of the analysis software such as MacCladeC and Sequencher(C) can also be quite expensive. There is however, some freeware available, for example Clustal (Thompson et al. 1994).

For the present cost benefit analysis, laboratory equipment, including computers and software has not been factored in, as it was available.

\section{Cost Ratings (in AUD per year) \\ $1=>\$ 10,000.2=>\$ 3000$ and $<\$ 10,000.3=$ under $\$ 3000$.}

2. Investment in Time = Time is defined in terms of days, weeks, months to gather the data, to train the researcher to use the methodology and to perform the analysis.

Time for collection of specimens for any study will depend largely on the project scope as addressed above. If a project is limited to a single geographic locality, and the specimens are known to be available at a certain time, then the time investment can be minimal. However, if a project includes a wide geographic range, or a large sampling of populations, with scuba diving required for example, then the time investment will be far greater than with a more narrowly constrained project.

Another investment in time for acquiring each of these data sets is for training in each of the areas of research. In order to utilize any of the data sets, it is 
necessary for the researcher to have some basic and some advanced skills. Specific examples follow.

(a) Gross Morphology: Morphology is perhaps one of the most time-consuming methods to learn and perform well enough for taxonomic studies. Dissection techniques, basic anatomy and biological illustration are tools acquired during most biology course work. Perfecting these skills and learning the techniques required for specific organisms could be quite time consuming especially for small organisms. Developing well thought out characters and then coding them for a phylogenetic analysis is also extremely time consuming. A mentor is important for this component.

(b) Ultrastructural investigations: With regard to training for sperm morphological studies, it is assumed that the researcher has a basic knowledge of microscopy skills. Learning the more advanced methodology required for transmission electron microscopy, such as processing, sectioning, staining and use of TEM microscopes is required. Accumulating enough data for a study on the cellular level, such as for comparative sperm morphology, can require a large investment of time. Detailed guidance from a microscopist is also invaluable for TEM work.

(c) DNA sequences (COI): A researcher trained in laboratory competence can acquire molecular laboratory skills in a reasonable amount of time. That is, a researcher is able to extract, amplify, sequence and align at least a 20-40 specimen sample over a few months. The analysis and interpretation of the data takes additional time, as it requires a solid background in genetics, molecular systematics and advanced phylogenetic methods. Keeping up with and understanding the molecular systematics literature is also very timeconsuming because molecular analysis literature is expanding considerably.

(d) Natural Product Chemistry: With regard to chemistry a biology researcher with a limited biochemistry background would be hardpressed to interpret the sophisticated chemical analyses required for complex chemical compounds. Reliance on a chemistry mentor for the interpretive aspects of the chemical data set is necessary. However, learning the equipment and technical skills for the chemical extractions and isolations and scanning (flash columns, TLC, GC, HPLC and NMR) can be accomplished within a year or two, even while acquiring skills in other areas of a multi-discipline research project.

In the present paper, published results are analyzed to determine the required investment in time for acquisition of each data set [(a) morphology, (b) sperm ultrastructure (c) DNA sequence data and (d) biochemistry (natural product chemistry)]

\section{Time Ratings}

$1=$ Most time consuming, probably not possible (unless using a small sample size) if combined with any other newly developed data set, such as a natural products or morphological data set. $2=$ Can be completed within a typical research period, but the researcher will need extensive mentoring if combining another data set. $3=$ Can be completed even in conjunction with another data set, i.e. morphological or histological (ultrastructure investigations).

3. Efficiency = Gaining a reliable test or measure of evolutionary relationships.

For the purposes of the present cost benefit analysis, efficiency (gaining a reliable measure of evolutionary relationships) is measured by the ability to illustrate evolutionary relationships by means of a phylogenetic tree. Published studies have used each of the four components to examine evolutionary relationships with mixed results. (See the examples in the Introduction section).

It should be noted that molecular and natural product chemistry are both relatively new applications for evolutionary biology as compared to morphological studies dating back to Linnaeus (1767). Thus both disciplines are in the testing phase for elucidating evolution (Cimino and Ghiselin 2001).

Efficiency ratings in Table 1 are based on examination of the results of each data set used to infer a species-level phylogeny.

\section{Efficiency Ratings}

$I=$ Not apparent at present that this data will provide an efficient means of elucidating evolutionary relationships at species level. 2= Efficiencies demonstrated at higher levels, though more studies are needed. $3=$ A reliable means of testing evolutionary relationships even at species level of organism evolution as determined by a robust phylogeny (see 4 . below).

4. Robustness $=$ Strength of support for a hypothesis.

The present cost benefit analysis defines robustness as few, if any branch trichotomies and including high retention and consistency indices for a phylogenetic tree. Thus, in the present analysis, robustness ratings closely mirror the efficiency ratings.

Support, for the purposes of this analysis, is evaluated by consistency index (CI), retention index (RI), Bremer support for morphology-derived trees (Bremer 1994) and bootstrap values for DNA sequence-derived trees (Felsenstein 1985) and 
resolution of trichotomies. Computer analysis programs such as PAUP* provide these scores.

The data sets and published results are reviewed for strength of support for the hypotheses offered.

\section{Robustness Ratings \\ $1=$ Has not yet been shown to resolve ambiguous branching patterns, or to increase support, especially at higher taxonomic levels. $2=$ Some additional resolution has been demonstrated, but more work is required. $3=$ Resolves branching ambiguities and/or increases the CI and RI. The higher the RI, the higher the amount of synapomorphy in the data set. The CI measures the amount of homoplasy in the data set. The higher the score, the lower the homoplasy in the data set.}

\section{RESULTS AND DISCUSSION}

The results of the cost benefit analysis are summarized in Table 1. The higher the overall rating ( $1=$ low, $12=$ high), the more likely the data set will accomplish the ultimate goal of illuminating a robust phylogenetic hypothesis for an acceptable cost, with a reasonable investment in time and with the greatest efficiency.

The results of each data set are:

(a) Morphological data: Morphological data yielded species level trees with $\mathrm{CI}, \mathrm{RI}$ and Bremer support values close, though not as high as those achieved by DNA (COI) sequence data.

Since most of the material was already available through museum collections and had been examined for previous analyses (for example Fahey and Gosliner 2001) no additional collecting costs were associated with gross morphology.

Although morphology is one of the most timeconsuming methods to learn and perform well enough for taxonomic studies, for the reviewed project, morphological techniques had been acquired in advance.

In summary, the projects (Fahey 2003a and b) demonstrated that a well-constructed morphological analysis results in a very robust phylogeny that is strongly supported by molecular data. Cost and time issues are greatly reduced by having adequate material available for examination at the onset of a project.

The scores assigned to the morphology data set are: Cost $=2$, Time investment $=3$, Efficiency $=3$, Robustness $=3$. Total score $=11$.

(b) Ultrastructural data: No sperm characters that could be used to unite the clade Halgerda were found (See Fahey and Healy 2003). Considerable diversity was observed in sperm morphology among species of Halgerda. Thus the results could not be mapped onto a phylogeny to test robustness of the data.

It was necessary to recollect all specimens examined in order to process them for histology (sperm ultrastructure investigations). Thus for this component, fieldwork contributed to the overall cost as did the smaller costs associated with chemicals, processing and photography.

The time to learn this aspect of the research was achieved in two years. Skills were learned during the first year with further material collected, processed and analyzed during the following year.

In summary, by itself sperm ultrastructure on the species level within the Discodorididae does not appear to provide enough discriminating phylogenetic information. Thus, sperm ultrastructure was less useful as an analytical tool for phylogenetic relationships for clades within the study group. However, the results of this study provided other insights. For example, the study supported the use of the outgroups, Asteronotus and Discodoris for phylogenetic studies of Halgerda. The sperm morphology between the study group and the outgroup taxa were more similar to each other than to other nudibranchs. Thus, succeeding phylogenetic analyses of the discodorids could utilize these taxa as outgroup or ingroup species.

The scores assigned to the ultrastructure data set are: Cost $=1$, Time investment $=3$, Efficiency $=2$, Robustness $=2$. Total score $=8$.

(c) DNA sequence (COI) data: Phylogenetic trees derived from molecular data resolved branch trichotomies in a morphological tree (from Fahey and Gosliner 2001). The molecular-based trees had higher $\mathrm{CI}$ and RI scores than found in trees derived

Table 1 Results of cost benefit analysis. The higher the overall rating, the more likely the data set can be successfully applied to the reconstruction of phylogeny for an acceptable cost, investment in time and with the greatest efficiency. 1 = low score, 2 = mid-range, 3 = high score. *Assumes some amount of ethyl alcohol-preserved material is available.

\begin{tabular}{lccccc} 
& Cost & Time Investment & Efficiency & Robustness & $\begin{array}{c}\text { Overall rating } \\
\text { (out of 12) }\end{array}$ \\
\hline Gross Morphology & $2^{*}$ & 3 & 3 & 3 & 11 \\
Sperm Ultrastructure & 1 & 3 & 2 & 2 & 8 \\
DNA sequences (COI) & $2^{*}$ & 3 & 3 & 3 & 11 \\
Natural Product Chemistry & 1 & 1 & 2 & 2 & 6 \\
\hline
\end{tabular}


from a morphological data set (Fahey 2003a and b). Thus, an improved existing phylogenetic hypothesis of Halgerda was gained. When molecular data were combined with morphological data (Fahey 2003a) the resulting trees had lower CI and RI scores than for trees derived from either morphological or molecular data alone.

For the cost considerations, specimens had to be recollected to obtain fresh tissue. Small clippings of mantle tissue were taken and voucher specimens were retained (See Fahey 2003a and b).

The time to learn the molecular laboratory protocols required the least amount of time (two months), with the data analysis portion taking several additional months.

In summary, the results of the cost benefit analysis show that $\mathrm{COI}$ is very useful for estimating evolutionary relationships between species of a clade, and indeed support the major clades of the morphology-based phylogenetic analyses (see Fahey, 2003a for specific details). A bettersupported hypothesis resulted, (more robust, higher bootstrap support), and in a very efficient manner (as defined in the Methods section). It appears that with sound morphological characters, a wellsupported phylogeny can be verified and supplemented by the use of molecular data. Furthermore, inter-specific analysis of the COI gene can be easily accomplished within a relatively short time frame. Collection of fresh material for DNA extraction appears to be the major challenge in order to utilize molecular data across a lower-level clade, as well as taxon sampling for rare, but critical taxa in elucidating phylogeny (Fahey 2003a).

Finally, analyses of molecular data allowed the examination of morphological character evolution. The results of the COI analysis showed two examples of a change in the tree topology as compared to analysis of morphological data (Fahey 2003a). In these cases there were few morphological characters that supported the clade in question, (i.e. Halgerda okinawa plus $H$. theobroma). A review of the morphological characters supporting the clades indicated that color characters might not be adequate to support the placement of these two species. The need to reassess characters or add additional characters was illuminated.

The results of the present study suggest that the same combination of data (morphological and COI sequence) could be used for other nudibranchs or organisms to develop new or examine existing phylogenies.

The scores assigned to the DNA sequence data set are: Cost $=2$, Time investment $=3$, Efficiency $=3$, Robustness $=3$. Total score $=11$.

(c) Natural product chemistry data: The results of analyses of the natural products of the clade Halgerdidae, (including Halgerda) (Fahey and Garson 2002; Fahey 2003b) showed that although
Halgerda shares some common characteristics with other closely related cryptobranch dorids, specific chemical compounds could not be identified among species of Halgerda and thus could not be mapped onto the phylogeny of the clade. Thus the robustness of a phylogenetic tree (Fahey and Gosliner 2001) could not be tested using natural products as characters.

Specimen collection was also required for the chemistry component. Larger amounts of the organism were required for extractions than for the other data sets. Thus the costs associated with sample collection contributed to the greatest extent for this aspect. (See Fahey and Garson 2002 and Fahey 2003b).

With regard to time investment, the limited conclusive chemical data obtained for Halgerda (Fahey 2003b) demonstrated that obtaining speciesspecific phylogenetic information is not as achievable in the same time frame as is possible using molecular-based information (See Fahey and Garson 2002; Fahey 2003a and b). Higher-level data however appear more within range of a shorter project (See for example Cimino and Ghiselin 1998, 1999,2001 ). If the nudibranch (or other organism of interest) and its prey are readily available and if the chemical compounds are known compounds, then the task of doing a species-level phylogeny based on chemistry could be completed within a shorter timeframe. But, when the animals are uncommon and the compounds are unknown in the literature, or are difficult to isolate due to small sample size, or complexity of the compound, as was the case for this study, substantial difficulties arise in achieving the desired outcome within a reasonable period, say two to three years. The time it takes to identify the myriad of signals in a small amount of material can exceed or exhaust a short timeframe. This is especially true if the researcher is developing multiple data sets (such as those discussed herein) at the same time.

In summary, even given the limitations and constraints outlined above, some general insights were made possible from biochemical studies (Fahey 2003b). For example, the cryptobranch nudibranch Halgerda was found to share feeding characteristics and compounds such as sterols, carotinoids and fatty acids with other cryptobranch nudibranchs (See Fahey 2003b for specific details). These shared qualities can be used as characters in a phylogenetic analysis of the cryptobranch dorids.

The scores assigned to the chemical data set are: Cost $=1$, Time investment $=1$, Efficiency $=2$, Robustness $=2$. Total score $=6$.

In conclusion, the results show that for the cost and time investment, morphological and molecular methods serve the nudibranch researcher well when undertaking a project that investigates phylogenetic relationships at the species level. Both methodologies 
scored 11 out of a possible 12 points. Sperm ultrastructure investigations (score 8 out of a possible 12) and natural product chemistry (score 6 out of a possible 12) can be valuable at higher taxonomic levels and should be pursued, especially if time can be devoted to developing those data sets exclusively.

The present cost benefit analysis of the cited studies shows that examination of multiple data sets can provide valuable insights into evolutionary relationships, allowing the researcher to further examine the hypothesis from various perspectives. In addition, a more robust phylogeny, as defined for the purposes of this study, can be achieved by combining data sets, particularly morphological and DNA sequence data.

\section{ACKNOWLEDGEMENTS}

The National Science Foundation, USA, Partnership for Enhancing Expertise in Taxonomy (PEET) grant, DEB 9978155, (Systematics of the Nudibranchia) to Dr T. Gosliner and by the Australian Federation of University Women (Freda Bage Scholarship) provided financial support for this study. Thanks are also due to the School of Molecular and Microbial Sciences, University of Queensland and to Dr John Healy, Queensland Museum for their support during this study. Drs Michael Ghiselin (California Academy of Sciences) and John Stanisic (Queensland Museum) examined the thesis from which the present material was taken and provided constructive comments.

\section{REFERENCES}

Avila, C. (1992). A preliminary catalogue of natural substances of opisthobranch molluscs from Western Mediterranean and near Atlantic. Scientia Marina 56: 373-382.

Avise, J. C. (1994). Molecular Markers, Natural History and Evolution. Chapman \& Hall. New York.

Ballard, J. and Whitlock, M. (2004). The incomplete natural history of mitochondria. Molecular Ecology 13: 729-744.

Bergh, R. (1891). Die cryptobranchiaten Dorididen. Zoologische Jahrbücher Abtheilung für Systematik, Geographie und Biologie der Tiere 6: 103-144.

Bremer, B. and Struwe, L. (1992). Phylogeny of the Rubiaceae and the Loganiaceae: Congruence or conflict between morphological and molecular data? American Joumal of Botany 79: 1171-1184.

Bremer, K. (1994). Branch support and tree stability. Cladistics 10: 295-304.

Brunckhorst, D. J. (1993). The systematics and phylogeny of phyllidiid nudibranchs (Doridoidea). Records of the Australian Museum Supplement 16: 1-107.

Cimino, G., Fontana, A. and Gavagnin, M. (1999). Marine Opisthobranch Molluscs: Chemistry and Ecology in Sacoglossans and Dorids. Current Organic Chemistry 3: 327-372.
Cimino, G. and Ghiselin, M. (2001). Marine Natural Products Chemistry as an Evolutionary Narrative. In J.A.B. McClintock (ed), Marine Chemical Ecology, 115154. CRC Press, New York.

Cimino, G. and Ghiselin, M. T. (1998). Chemical defense and evolution in the Sacoglossa (Mollusca: Gastropoda: Opisthobranchia). Chemoecology 8: 51-60.

Cimino, G. and Ghiselin, M. T. (1999). Chemical defense and evolutionary trends in biosynthetic capacity among dorid nudibranchs (Mollusca: Gastropoda: Opisthobranchia). Chemoecology 9: 187-207.

Cimino, G. and Sodano, G. (1994). Transfer of sponge secondary metabolites to predators. In $\mathrm{R}$. VanSoest, T.M.G. VanKempen, J.C. Braekman. (eds), Sponges in Time and Space, 459-472. Balkema, Rotterdam.

Cracraft, J. and Helm-Bychowski, K. (1991). Parsimony and phylogenetic Inference using DNA Sequences: Some Methodological Strategies. In M. Miyamoto, J. Cracraft. (eds), Phylogenetic Analysis of DNA Sequences, 184-220. Oxford University Press, New York.

de Queiroz, K., Donoghue, M. J. and Kim, J. (1995). Separate versus combined analysis of phylogenetic evidence. Annual Review of Ecology and Systematics 26: 657-681.

de Queiroz, K. and Gauthier, J. (1990). Phylogeny as a central principle in taxonomy: Phylogenetic definitions of taxon names. Systematic Zoology 39: 307322.

Dorgan, K., Valdés, A. and Gosliner, T. (2002). Phylogenetic systematics of the genus Platydoris (Mollusca: Nudibranchia: Doridoidea) with descriptions of six new species. Zoologica Scripta 31: 271-319.

Eckelbarger, K. J. (1982). Undulating arrays of endoplasmic reticulum in the spermatids of an opisthobranch mollusc. Tissue and Cell 14: 289-295.

Eckelbarger, K. J. and Eyster, L. S. (1981). An ultrastructural study of spermatogenesis in the nudibranch mollusc Spurilla neapolitana. Journal of Morphology 170: 283-299.

Fahey, S. and Gosliner, T. (2001). The phylogeny of Halgerda (Opisthobranchia, Nudibranchia) with the description of a new species from Okinawa. Zoologica Scripta 30: 199-213.

Fahey, S. and Healy, J. (2003). Sperm ultrastructure in the nudibranch genus Halgerda with reference to other Discodorididae and to Chromodorididae (Mollusca: Opisthobranchia). Journal of Morphology 257: 9-21.

Fahey, S. J. (2003a). Combining traditional morphological character sets with molecular, sperm ultrastructure and biochemical data. Can this improve an evolutionary model? Ph.D. Thesis. School of Molecular and Microbial Sciences, The University of Queensland. Brisbane.

Fahey, S. J. (2003b). Phylogeny of Halgerda (Mollusca: Nudibranchia) based on combined analysis of mitochondrial COI and morphology. Invertebrate Systematics 17: 617-624.

Fahey, S. J. and Garson, M. J. (2002). Geographic variation of the natural products of the tropical nudibranch Asteronotus cespitosus. Journal of Chemical Ecology 28: 1761-1773.

Fahey, S. J. and Gosliner, T. M. (2003). Mistaken 
identities: On the Discodorididae genera Hoplodoris Bergh, 1880 and Carminodoris Bergh, 1889 (Opisthobranchia, Nudibranchia). Proceedings of the California Academy of Sciences 54: 169-208.

Farris, J. S. (1983). The logical basis of phylogenetic analysis. In N. Platnick, V. Funk. (eds), Advances in Cladistics, 2: 7-36. Columbia University Press, New York.

Faulkner, D. J. 1996. Marine Natural Products. In Natural Product Reports. 75-125. Vol. 12. Scripps Institute of Oceanography, La Jolla.

Faulkner, D. J. 1997. Marine Natural Products. In Natural Product Reports. 259-302. Vol. 13. Scripps Institute of Oceanography, La Jolla.

Faulkner, D. J. 1998. Marine Natural Products. In Natural Product Reports. 113-158. Vol. 14. Scripps Institute of Oceanography, La Jolla.

Faulkner, D. J. 1999. Marine Natural Products. In Natural Product Reports. pp. 155-198. Vol. 16. Scripps Institute of Oceanography, La Jolla.

Faulkner, D. J. 2000a. Highlights of marine natural products chemistry (1972-1999). In Natural Product Reports. pp. 1-6. Vol. 17. Scripps Institute of Oceanography, La Jolla.

Faulkner, D. J. 2000b. Marine Natural Products. In Natural Product Reports. 7-55. Vol. 17. Scripps Institute of Oceanography, La Jolla.

Faulkner, D. J. 2001. Marine Natural Products. In Natural Product Reports. 1-49. Vol. 18. Scripps Institute of Oceanography, La Jolla.

Faulkner, D. J. and Ghiselin, M. T. (1983). Chemical defense and evolutionary ecology of dorid nudibranchs and some other opisthobranch gastropods. Marine Ecology-Progress Series 13: 295-301.

Felsenstein, J. (1985). Confidence limits on phylogenies: An approach using the bootstrap. Evolution 39: 383791.

Garovoy, J., Valdés, A. and Gosliner, T. (2001). Phylogeny of the genus Rostanga (Mollusca, Nudibranchia), with descriptions of three new species from South Africa. Journal of Molluscan Studies 67: 131-144.

Giusti, F. (1971). L'ultrastruttura dello spermatozoo nella filogenesi e nella sistematica dei molluschi gasteropodi. Atti della Società Italiana di Scienze Naturali e Museo Civico di Storia Naturale Milano 112: 381-402.

Giusti, F. and Selmi, M. G. (1982). The morphological peculiarities of the typical spermatozoa of Theodoxus fluviatilis (L.) (Neritoidea) and their implications for motility. Journal of Ultrastructure Research 78: 166177.

Gosliner, T. and Johnson, R. (1999). Phylogeny of Hypselodoris (Nudibranchia: Chromodorididae) with a review of the monophyletic clade of Indo-Pacific species, including descriptions of twelve new species. Zoological Journal of the Linnean Society 125: 1-114.

Gosliner, T. and Johnson, S. (1994). Review of the genus Hallaxa (Nudibranchia: Actinocyclidae) with descriptions of nine new species. The Veliger 37: 155191.

Gosliner, T. M. (1996). Phylogeny of Ceratosoma (Nudibranchia: Chromorididae), with descriptions of two new species. Proceedings of The California Acadenty of Sciences 49: 115-126.

Gosliner, T. M. (2004). Phylogenetic systematics of Okenia, Sakishimaia, Hopkinsiella and Hopkinsia (Nudibranchia: Goniodorididae) with descriptions of new species from the tropical Indo-Pacific. Proceedings of the California Academy of Sciences 55: 125-161.

Grande, C., Templado, J., Cervera, J. and Zaroya, R. (2004). Phylogenetic relationships among Opisthobranchia (Mollusca: Gastropoda) based on mitochondrial $\operatorname{cox} 1, \operatorname{trn} V$, and $r r n L$ genes. Molecular Phylogenetics and Evolution 33: 378-388.

Healy, J. (1984). The ultrastructure of gastropod spermatozoa and spermiogenesis. Ph.D. Thesis. Department of Zoology, University of Queensland, Brisbane.

Healy, J. (1988a). Sperm morphology and its systematic importance in the Gastropoda. In W. Ponder. (ed), Prosobranch Phylogeny, Malacological Review, Supplement 4: 251-266. University of Michigan Press, Ann Arbour.

Healy, J. M. (1987). Spermatozoan ultrastructure and its bearing on gastropod classification and evolution. Australian Zoologist 24: 108-113.

Healy, J. M. (1988b). The ultrastructure of spermatozoa and spermiogenesis in pyramidellid gastropods, and its systematic importance. Helgoländer Meeresuntersuchungen 42: 303-318.

Healy, J. M. and Willan, R. C. (1984). Ultrastructure and phylogenetic significance of notaspidean spermatozoa (Mollusca, Gastropoda, Opisthobranchia). Zoologica Scripta 13: 107-120.

Healy, J. M. and Willan, R. C. (1991). Nudibranch spermatozoa: comparative ultrastructure and systematic importance. The Veliger 34: 134-165.

Hillis, D. H. (1987). Molecular versus morphological approaches to systematics. Annual Review of Ecology and Systematics 18: 23-42.

Hodgson, A. N. and Bernard, R. T. F. (1988). A comparison of the structure of the spermatozoa and spermatogenesis for 16 species of patellid limpet (Mollusca: Gastropoda: Archaeogastropoda). Journal of Morphology 195: 205-223.

Holman, J. A. (1972). The ultrastructure and activity of sperm in Acanthodoris pilosa, a nudibranch mollusk. Marine Biology 12: 179-183.

Idler, D. R., Khalil, M. W., Brooks, C. J., Edmonds, C. G. and Gilbert, J. D. (1978). Studies of sterols from marine molluscs by gas chromatography and mass spectrometry. Comparative Biochemistry and Physiology 59B: 163-167.

Karuso, P. (1987). Chemical ecology of the nudibranchs. In P. Scheuer. (ed), Bioorganic Marine Chemistry, 1: 3160. Springer, Berlin.

Kohnert, R. and Storch, V. (1984). Vergleichendultrastrukturelle Untersuchungen zur Morphologie eupyrener Spermien der Monotocardia (Prosobranchia). Zoologischer Jahrbucher 111: 51-93.

Koike, K. (1985). Comparative ultrastructural studies on the spermatozoa of the Prosobranchia (Mollusca: Gastropoda). Science Reports of the Faculty of Education, Gunma University, Japan 34: 33-153.

Linnaeus, C. (1767). Systema Naturae. Holmiae. Salvii. 
Medina, A., Moreno, J. and Lopez-Campos, J. L. (1985). Acrosome evolution in Hypselodoris tricolor (Gastropoda: Nudibranchia). Journal of Submicroscopic Cytology 17: 403-411.

Medina, A., Moreno, J. and Lopez-Campos, J. L. (1986). Nuclear morphogenesis during spermiogenesis in the nudibranch mollusc Hypselodoris tricolor (Gastropoda, Opisthobranchia). Gamete Research 13: 159-171.

Medina, M. and Walsh, P. J. (2000). Molecular systematics of the Order Anaspidea based on mitochondrial DNA sequence (12S, 16S, and COI). Molecular Phylogenetics and Evolution 15: 41-58.

Moritz, C. and Hillis, D. (1996). Molecular Systematics: Context and Controversies. In D. Hillis, C. Moritz, B. Mable. (eds), Molecular Systematics, 1-13. Sinauer Associates, Inc, Sunderland.

Nixon, K. and Carpenter, J. (1996). On simultaneous analysis. Cladistics 12: 221-241.

Penny, D., Hendy, M. D. and Steel, M. A. (1991). Testing the Theory of Descent. In M.M. Miyamoto, J. Cracraft. (eds), Phylogenetic Analysis of DNA Sequences, 155-183. Oxford University Press, New York.

Ponder, W. F. and Lindberg, D. R. (1995). Gastropod phylogeny - challenges for the 90s. In J.D. Taylor. (ed), Origin and evolutionary radiation of the Mollusca, 135-154. Oxford University Press, Oxford.

Schmekel, L. (1971). Histologie und Feinstruktur der Genitalorgane von Nudibranchiern (Gastropoda, Euthyneura). Zoologischen Morphologie Tiere 69: 115183.

Swofford, D. L. (1991). When are phylogeny estimates from molecular and morphological data incongruent? In M.M. Miyamoto, J. Cracraft. (eds), Phylogenetic Analysis of DNA Sequences, 295-333. Oxford University Press, New York.

Thollesson, M. (1998). Nudibranch Systematics and Molecular Data. Ph.D. Thesis. Faculty of Natural Sciences, Göteborg University. Göteborg.

Thollesson, M. (1999a). Phylogenetic analysis of dorid nudibranchs (Gastropoda: Doridacea) using the mitochondrial 16s rRNA gene. Journal of Molluscan Studies 65: 335-353.

Thollesson, M. (1999b). Phylogenetic analysis of Euthyneura (Gastropoda) by means of the $16 \mathrm{~S}$ rRNA gene: use of a 'fast' gene for 'higher-level' phylogenies. Proceedings of The Royal Society of London Series B Biological Sciences. 266: 75-83.
Thompson, J. D. and Higgins, D. G. and Gibson, T. J. (1994). ClustalW: Improving the sensitivity of progressive multiple sequence alignment through sequence weighting, position, specific gap penalties, and weight matrix choice. Nucleic Acids Research 22: 4673-4680.

Thompson, T. E. (1966). Studies on the reproduction of Archidoris pseudoargus Rapp (Gastropoda: Opisthobranchia). Philosophical Transactions of the Royal Society of London 250: 343-375.

Thompson, T. E. (1973). Euthyneuran and other molluscan spermatozoa. Malacologia 14: 167-206, addendum 443-444.

Valdés, A. (2002). A phylogenetic analysis and systematic revision of the cryptobranch dorids (Mollusca, Nudibranchia, Anthobranchia). Zoological Journal of the Linnean Society, London 136: 535-636.

Valdés, A. (2004). Phylogeography and phylogecology of dorid nudibranchs (Mollusca, Gastropoda). Biological Journal of the Linnaen Society 83: 551-559.

Valdés, A. and Gosliner, T. M. (1999). Phylogeny of the radula-less dorids (Mollusca, Nudibranchia), with the descriptions of a new genus and a new family. Zoologica Scripta 28: 315-360.

Valdés, A. and Gosliner, T. M. (2001). Systematics and phylogeny of the caryophyllidia-bearing dorids (Mollusca, Nudibranchia), with the description of a new genus and four new species from the IndoPacific deep waters. Zoological Journal of the Linnean Society, London 133: 103-199.

Wägele, H., Vonnemann, V. and Wägele, W. (2003). Toward a phylogeny of the Opisthobranchia. In C. Lydeard and D.R. Lindberg (eds), Molecular Systematics and Phylogeography of Mollusks, 185-288. Smithsonian Books, Washington DC.

Wägele, H. and Willan, R. C. (2000). Phylogeny of the Nudibranchia. Zoological Journal of the Linnean Society 130: 83-181.

Wollscheid-Lengeling, E., Boore, J., Brown, W. and Wägele, H. (2001). The phylogeny of Nudibranchia (Opisthobranchia, Gastropoda, Mollusca) reconstructed by three molecular markers. Organisms Diversity \& Evolution 1: 241-256. 